\title{
Universiteit
}

Leiden

The Netherlands

\section{Enteral acetaminophen bioavailability in pediatric intensive care patients determined with an oral microtracer and pharmacokinetic modeling to pptimize dosing}

Kleiber, N.; Calvier, E.; Mooij, M.G.; Krekels, E.H.J.; Vaes, W.H.J.; Tibboel, D.; ... ; Wildt, S.N. de

\section{Citation}

Kleiber, N., Calvier, E., Mooij, M. G., Krekels, E. H. J., Vaes, W. H. J., Tibboel, D., ... Wildt, S. N. de. (2019). Enteral acetaminophen bioavailability in pediatric intensive care patients determined with an oral microtracer and pharmacokinetic modeling to pptimize dosing. Critical Care Medicine, 47(12), e975-e983. doi:10.1097/CCM.0000000000004032

Version:

Publisher's Version

License: Licensed under Article 25fa Copyright Act/Law (Amendment Taverne)

Downloaded from:

Note: To cite this publication please use the final published version (if applicable). 


\title{
Enteral Acetaminophen Bioavailability in Pediatric Intensive Care Patients Determined With an Oral Microtracer and Pharmacokinetic Modeling to Optimize Dosing
}

\author{
Niina Kleiber, $\mathrm{PhD}^{1,2}$; Elisa Calvier, $\mathrm{PhD}^{3}$; Miriam G. Mooij, $\mathrm{PhD}^{2,4}$; Elke H. J. Krekels, $\mathrm{PhD}^{3}$; \\ Wouter H. J. Vaes, $\mathrm{PhD}^{5}$; Dick Tibboel, $\mathrm{PhD}^{2}$; Catherijne A. J. Knibbe, $\mathrm{PhD}^{3}$; Saskia N. de Wildt, $\mathrm{PhD}^{2,6}$
}

\begin{abstract}
Objectives: Decreasing morbidity and mortality by rationalizing drug treatment in the critically ill is of paramount importance but challenging as the underlying clinical condition may lead to large variation in drug disposition and response. New microtracer methodology is now available to gain knowledge on drug disposition in the intensive care. On the basis of studies in healthy adults, physicians tend to assume that oral doses of acetaminophen will be completely absorbed and therefore prescribe the same dose per
\end{abstract}

'Division of General Pediatrics and Clinical Pharmacology Unit, Department of Pediatrics, Sainte-Justine Hospital, Université de Montréal, and Sainte-Justine Research Center, Montréal, OC, Canada.

${ }^{2}$ Intensive Care and Department of Pediatric Surgery, Erasmus MC-Sophia Children's Hospital, Rotterdam, The Netherlands.

${ }^{3}$ Division of Pharmacology, Leiden Academic Centre for Drug Research (LACDR), Leiden University, Einsteinweg, Leiden, The Netherlands.

${ }^{4}$ Department of Pediatrics, Willem-Alexander Children's Hospital, Leiden University Medical Centre, Leiden, The Netherlands.

${ }^{5}$ TNO, Zeist, The Netherlands.

${ }^{6}$ Department of Pharmacology and Toxicology, Radboud University, Nijmegen, The Netherlands.

Drs. Kleiber and Calvier contributed equally to this work.

Drs. Knibbe and de Wildt contributed equally to this work.

Supplemental digital content is available for this article. Direct URL citations appear in the printed text and are provided in the HTML and PDF versions of this article on the journal's website (http://journals.lww.com/ ccmjournal).

Supported, in part, by grant from The Netherlands Organization for Health Research and Development research grant (113202007).

Drs. Krekels and de Wildt disclosed work for hire. Drs. Vaes's and de Wildt's institutions received funding from The Netherlands Organization for Health Research and Development (ZonMw). Dr. de Wildt's institution also received funding from TNO Zeist (consulting); she disclosed she is Director of the Dutch Knowledge Center for Pharmacotherapy in Children and as such is responsible for the dosing guidelines of paracetamol in the Dutch Pediatric Formulary; and she disclosed off-label product of paracetamol. The remaining authors have disclosed that they do not have any potential conflicts of interest.

For information regarding this article, E-mail: s.dewildt@erasmusmc.nl

Copyright (C) 2019 by the Society of Critical Care Medicine and Wolters Kluwer Health, Inc. All Rights Reserved.

DOI: $10.1097 / C C M .0000000000004032$ kilogram for oral and IV administration. As the oral bioavailability of acetaminophen in critically ill children is unknown, we designed a microtracer study to shed a light on this issue.

Design: An innovative microtracer study design with population pharmacokinetics.

Setting: A tertiary referral PICU.

Patients: Stable critically ill children, 0-6 years old, and already receiving IV acetaminophen.

Interventions: Concomitant administration of an oral ${ }^{14} \mathrm{C}$ radiolabeled acetaminophen microtracer $(3 \mathrm{ng} / \mathrm{kg})$ with IV acetaminophen treatment $(15 \mathrm{mg} / \mathrm{kg}$ every $6 \mathrm{hr}$ ).

Measurements: Blood was drawn from an indwelling arterial or central venous catheter up to 24 hours after ${ }^{14} \mathrm{C}$ acetaminophen microtracer administration. Acetaminophen concentrations were measured by liquid chromatography-mass spectrometry and ${ }^{14} \mathrm{C}$ concentrations by accelerated mass spectrometry.

Main Results: In 47 patients (median age of 6.1 mo; Q1-Q3, 1.8-20 mo) the mean enteral bioavailability was $72 \%$ (range, $11-91 \%)$. With a standard dose $(15 \mathrm{mg} / \mathrm{kg} 4$ times daily), therapeutic steady-state concentrations were 2.5 times more likely to be reached with IV than with oral administration.

Conclusions: Microtracer studies present a new opportunity to gain knowledge on drug disposition in the intensive care. Using this modality in children in the pediatric intensive care, we showed that enteral administration of acetaminophen results in less predictable exposure and higher likelihood of subtherapeutic blood concentration than does IV administration. IV dosing may be preferable to ensure adequate pain relief. (Crit Care Med 2019; 47:e975-e983)

Key Words: acetaminophen; analgesia; children; pain; pediatric intensive care; pharmacokinetics

To decrease morbidity and mortality, critically ill patients ideally require optimized drug effect with minimized adverse effects. But their underlying condition leads to a large variation in drug disposition and response which 
complicates drug choice and dosing (1). As an example, enteral drug dosing in the critically ill is commonly derived from bioavailability studies in healthy volunteers but does not take into account the change in disposition associated with the delayed gastric emptying, hemodynamic instability, and change in gastric $\mathrm{pH}$ often found in these patients $(2,3)$. Dedicated research in the ICU population is therefore of paramount importance to optimize dosing and choice of route of administration. But the extraordinary environment of the ICU raises specific challenges to the design and conduct of research that limit drug research (4). Oral bioavailability is traditionally estimated with crossover studies, by giving a drug dose first via the oral or IV route and then, after washout of the first dose, the same dose in the same patient via the alternate route. After each dose, multiple blood samples are taken to estimate pharmacokinetic variables. The ratio of area under the curves (AUCs) after oral and IV dosing defines the oral bioavailability. Applying this method in the ICU only for research purposes is neither ethically acceptable nor feasible (4). Alternatively, replacing an IV dose by an oral dose during repeated drug dosing is suboptimal, as a patient's clinical situation may change rapidly, resulting in imprecise bioavailability estimations. New techniques allow overcoming these hurdles and offer new opportunities for optimal drug dosing in the ICU. We recently showed the feasibility of a radioactive labeled microtracer study to evaluate pharmacokinetics in children $(5,6)$. The use of this innovative method is endorsed by the European Medicines Agency and the Food and Drug Administration (7). To study oral bioavailability, a labeled nontherapeutic microtracer $(<1 / 100$ of therapeutic dose) can be given enterally to a patient receiving IV acetaminophen for treatment as per clinical practice, with extremely low radioactive exposure. The oral microtracer is exactly the same molecule, but it contains radioactive carbon isotope $\left({ }^{14} \mathrm{C}\right)$ permitting differentiation from the IV treatment dose given at the same time. This microtracer is associated with a very low radiation exposure, that is, 1 microSv for a microdose in a neonate compared with 40 microSv for a single flight from Europe to the United States (8).

Sick children receive $15 \%$ of the drugs orally despite absent bioavailability data (9) including acetaminophen, an effective analgesic (10), and antipyretic (11). When available, IV acetaminophen is increasingly prescribed by pediatric intensivists. It offers an advantage when the enteral route may not be tolerated. It is unclear whether it should be preferred over the oral route (12) in children tolerating enteral drug administration as acetaminophen oral bioavailability data in children are lacking. Most physicians prescribe the same oral and IV doses as recommended in labeled dosing guidelines $(60 \mathrm{mg} / \mathrm{kg} / \mathrm{d}$; maximum dose: $1 \mathrm{~g})$. Achieving similar drug exposure with oral and IV routes would only be possible, if absorption is nearly complete in all patients (complete bioavailability with small interpatient variability). Yet, bioavailability estimations in studies in healthy volunteers range from $60 \%$ to $97 \%$ (13-15). Critically ill children will likely show a higher variability (16).
We therefore aimed to estimate the oral bioavailability of acetaminophen in the pediatric intensive care using the innovative ${ }^{14} \mathrm{C}$ microtracer approach.

\section{METHODS}

\section{Setting}

This prospective study was embedded in a larger ${ }^{14} \mathrm{C}$ microtracer study $(5,6,8)$ carried out in tertiary care PICU of the Erasmus MC-Sophia Children's Hospital. The Dutch Central Committee on Research Involving Human Subjects approved the study. Parental written informed consent was obtained.

\section{Population}

All patients up to 6 years old admitted to the PICU who received IV acetaminophen and had an arterial or central venous catheter in place were eligible $(5,6)$. To minimize interindividual variability due to critical illness, the exclusion criteria were defined to obtain a subpopulation with low disease severity. These criteria were renal disorder (according to pediatric Risk, Injury, Failure, Loss, End-Stage Renal Disease [pRIFLE] criteria, an estimated creatinine clearance decrease by $25 \%$ or more compared with a baseline prior to study inclusion or urine output of less than $0.5 \mathrm{~mL} /$ $\mathrm{kg}$ per hour for $8 \mathrm{hr}$ [17]) and liver failure (> $2 \mathrm{SD}$ in age-appropriate liver enzyme measurement [aspartate aminotransferase and alanine aminotransferase]), gastrointestinal disorder (ileus, diarrhea, any underlying bowel disease, pancreatic insufficiency), coadministration of drugs known to interact with acetaminophen pharmacokinetics, the use of more than one vasopressor drug and extracorporeal membrane oxygenation. Introduction and progression of feeds were left at the discretion of the treating physician.

\section{Study Design}

A single dose of enteral acetaminophen-containing radioactive carbon isotope (radiolabeled microtracer dose: $\left[{ }^{14} \mathrm{C}\right]$ acetaminophen at $3.3 \mathrm{ng} / \mathrm{kg}, 60 \mathrm{~Bq} / \mathrm{kg}, 0.25 \mathrm{~mL} / \mathrm{kg}$ ) oral acetaminophen was administered by the researcher simultaneously with the IV acetaminophen treatment given by the bedside nurse IV (Fresenius Kabi, Schelle, Belgium; $10 \mathrm{mg} / \mathrm{mL}$ ) (5). The oral microdose was derived from a previous healthy adult $\left[{ }^{14} \mathrm{C}\right]$ acetaminophen microdose study $(18)$. The $\left[{ }^{14} \mathrm{C}\right]$ acetaminophen formulation for oral administration was prepared by adding $\left[{ }^{14} \mathrm{C}\right]$ acetaminophen to an acetaminophen formulation for IV use (VU University Medical Center, Amsterdam; good manufacturing practice license number $\mathrm{NL} / \mathrm{H} 11 / 0005)$. The final concentrations were $13 \mathrm{ng} / \mathrm{mL}$ for $\left[{ }^{14} \mathrm{C}\right]$ acetaminophen and $6.7 \mu \mathrm{g} / \mathrm{mL}$ for nonlabeled acetaminophen both being negligible in relation to the IV treatment dose and thus considered irrelevant for the pharmacokinetic estimation of the IV acetaminophen pharmacokinetics. To ensure proper delivery to patients fed by a nasogastric tube, $1 \mathrm{~mL}$ of saline was used to flush the gastric tube. In vitro adhesion studies were carried out with this technique and showed that the amount recovered after the passage through the tube was greater than $95 \%$ and consistent with appropriate drug delivery to the gastrointestinal tract (5). A syringe was used to deliver the drug to orally fed patients. The IV acetaminophen 
treatment was dosed according to the Dutch Pediatric Handbook: $20 \mathrm{mg} / \mathrm{kg}$ loading dose, followed by $10 \mathrm{mg} / \mathrm{kg}$ q6h $(<1 \mathrm{mo}$ old) or $15 \mathrm{mg} / \mathrm{kg}$ q6h ( $\geq 1 \mathrm{mo}$ old) (19). The IV acetaminophen dose in $\mathrm{mg}$ was rounded to the nearest integer, and it was prepared and double-checked in the pharmacy. Some children had already received multiple doses before the microtracer dose was given and information on these doses was included in the pharmacokinetic analysis.

Blood samples $(1 \mathrm{~mL})$ were drawn from the indwelling catheter just before administration of the acetaminophen microtracer dose and at 10 and 30 minutes, and 1, 2, 4, 6, 12, 24 hours after administration. After centrifugation, plasma was stored at $-80^{\circ} \mathrm{C}$.

\section{Measurements}

$\left[{ }^{14} \mathrm{C}\right]$ acetaminophen plasma concentrations were measured by liquid chromatography-accelerator mass spectrometry (LC + AMS) as previously described $(5,20)$. The LC + AMS qualification was performed in accordance with the recommendation of the European Bioanalytical Forum (21). Three quality control (QC) concentration levels were included as follows: QC high $145 \mathrm{mBq} / \mathrm{mL}$, QC medium $14.5 \mathrm{mBq} / \mathrm{mL}$, and QC low $2.4 \mathrm{mBq} / \mathrm{mL}$. The accuracy of QC high, medium, and low analysis corresponded to $104 \%, 103 \%$, and $90 \%$, respectively. The precisions, defined by a coefficient of variation (CV) of $9.1 \%$, $6.7 \%$, and $6.9 \%$, respectively, were within the requirements for LC + AMS analysis (21). The lower limit of quantification (LLOQ) of the method was $0.58 \mathrm{mBq} / \mathrm{mL}$ (5). Treatment acetaminophen plasma concentrations were measured by liquid chromatography-mass spectrometry. The LLOQ for cold (nonradioactive) acetaminophen was $0.05 \mathrm{mg} / \mathrm{L}$. Mean intraand inter-assay accuracy ranged from $85 \%$ to $111 \%$, and intraand inter-assay imprecision did not exceed 15\% CV.

\section{DATA ANALYSIS}

\section{Pharmacokinetic Analysis}

Population pharmacokinetic analysis was performed using the nonlinear mixed-effect modeling NONMEM 7.3.0 software (Icon Development Solutions, Ellicott City, MD). Log transformed treatment and $\left[{ }^{14} \mathrm{C}\right]$ acetaminophen concentrations were modeled simultaneously. A structural pharmacokinetic model was developed to describe the typical pharmacokinetic variables, including $\mathrm{F}$ (oral bioavailability), together with a statistical model providing for the unexplained interindividual variability. Then, potential covariates were tested for statistical significance. These covariates are clinical characteristics to be taken into account for individualized dosing. In pediatrics, weight is included in most models, and therefore, doses are calculated per kilograms. Other patient characteristics (described in Table 1) that significantly decreased the interindividual variability of pharmacokinetic variables were included in the model to target dosing to these characteristics. To account for exposure from the rectal doses given prior to inclusion, the absorption rate, and lag time for this administration route were fixed to literature values (22) and bioavailability was estimated. One, two, and three compartment models, first and zero order oral absorption and an oral absorption lag time were tested. The details of the analysis are provided in the eMethods (Supplemental Digital Content 1, http://links.lww.com/CCM/E943).

\section{Dosing Simulations}

To compare systemic exposure (plasma concentrations) after oral and IV administration, the concentration-time profiles until 24 hours after administration and mean steady-state concentrations (Css) were simulated based on Monte-Carlo simulations using the validated pharmacokinetic model estimates from the current analysis. The average concentration at steady state was calculated by dividing the AUC over the dosing interval by the dosing time interval.

The simulated dosing regimen was as follows: similar oral and IV doses of $15 \mathrm{mg} / \mathrm{kg}$ per dose every $6 \mathrm{hr}(60 \mathrm{mg} / \mathrm{kg} / \mathrm{d})(23)$. The highest recommended oral dosing regimen of $22.5 \mathrm{mg} / \mathrm{kg} / \mathrm{dose}$ every 6 hours $(90 \mathrm{mg} / \mathrm{kg} / \mathrm{d})$ was also simulated (19). Simulations were performed for four age groups: 1 month, 6 months, 1 year, and 5 years, assuming a typical weight of $4.5,8,10$, and $18 \mathrm{~kg}$, respectively, according to the Centers for Disease Control and Prevention growth charts. For each dosing regimen and age group, 1,000 simulations were performed taking into account interindividual variability in the model variables. For each simulation, the mean Css was computed based on the dose and the sampled individual clearance variable, as well as the sampled individual bioavailability variable for oral administration. The median as well as the 5th and 95th percentiles of the concentration-time profiles and of the mean Css were plotted for each dosing and age group.

A mean Css of $10 \mathrm{mg} / \mathrm{L}( \pm 20 \% \mathrm{SD})$ was targeted. This threshold is based on two studies by Anderson et al $(24,25)$ on a total of 220 children who received acetaminophen after tonsillectomy (with or without adenoidectomy). They showed adequate analgesia with a steep decrease in pain scores when concentrations increased up to $10 \mathrm{mg} / \mathrm{mL}$ and only a marginal decrease in pain scores at higher concentrations. Despite scarce data, dosing regimens in children are generally designed to reach an average Css of $10 \mathrm{mg} / \mathrm{L}(26,27)$. Based on the MonteCarlo simulations, the percentage of patients reaching the targeted mean Css of $10 \mathrm{mg} / \mathrm{L} \pm 20 \%(8-12 \mathrm{mg} / \mathrm{L})$ in the IV acetaminophen group and in the enteral acetaminophen group was computed for the four age groups.

\section{RESULTS}

\section{Population}

As depicted in Supplemental Figure 1 (Supplemental Digital Content 2, http://links.lww.com/CCM/E944; legend, Supplemental Digital Content 5, http://links.lww.com/CCM/E947), among 232 eligible patients, a total of 118 were excluded, of whom 60 on the basis of exclusion criteria; for 21 patients the study drug was unavailable (outside office hours of pharmacy) and 37 patients participated in another clinical trial (6). Of the 114 parents/carers approached, 64 declined participation of their child and thus 50 patients were enrolled. Two patients were excluded after inclusion as they vomited shortly after 


\section{TABLE 1. Covariates Tested for Their Influence on Pharmacokinetics Variables}

\begin{tabular}{|c|c|c|}
\hline $\begin{array}{l}\text { Type of Data } \\
\text { Collected }\end{array}$ & Reason for Collection & Potential Covariates \\
\hline \multirow[t]{2}{*}{ Weight } & \multirow{2}{*}{$\begin{array}{l}\text { Weight is often found a major predictor of } \\
\text { pharmacokinetics variability in pediatric } \\
\text { patients }\end{array}$} & Weight at study day \\
\hline & & Weight SD from 50th percentile for age and sex \\
\hline \multirow[t]{3}{*}{ Maturation } & \multirow{3}{*}{$\begin{array}{l}\text { Age often found a major predictor of pharmaco- } \\
\text { kinetics variability in pediatric patients }\end{array}$} & Postnatal age \\
\hline & & Postmenstrual age \\
\hline & & Gestational age \\
\hline \multirow[t]{2}{*}{ Diagnostic } & $\begin{array}{l}\text { Surgery and associated opioid use induce ileus } \\
\text { that may influence oral absorption }\end{array}$ & Surgery \\
\hline & $\begin{array}{l}\text { Abdominal surgery induces gut edema and alters } \\
\text { intestinal perfusion }\end{array}$ & Abdominal surgery \\
\hline Severity of disease & $\begin{array}{l}\text { Severity of disease is associated to ileus, gut } \\
\text { edema, and altered gut perfusion }\end{array}$ & $\begin{array}{l}\text { Severity scores: PELOD score, Pediatric Risk of Mortality, } \\
\text { Pediatric Index of Mortality }\end{array}$ \\
\hline \multirow[t]{4}{*}{ Organ function } & \multirow[t]{4}{*}{ Organ failure may influence pharmacokinetics } & $\begin{array}{l}\text { Renal function: urea, creatinine } z \text { score adjusted for } \\
\text { gender and age }\end{array}$ \\
\hline & & $\begin{array}{l}\text { Liver function tests: alanine aminotransferase, aspartate } \\
\text { aminotransferase, alkaline phosphatase, bilirubin, } \\
\text { gamma-glutamyltransferase }\end{array}$ \\
\hline & & $\begin{array}{l}\text { Number of organ dysfunction: defined as the number of } \\
\text { organ with a positive PELOD score }\end{array}$ \\
\hline & & Other: albumin, lactate \\
\hline \multirow[t]{2}{*}{ Inflammation } & \multirow{2}{*}{$\begin{array}{l}\text { Inflammation may have a major impact on } \\
\text { pharmacokinetics }\end{array}$} & C-reactive protein \\
\hline & & Leucocytes \\
\hline $\begin{array}{l}\text { Way of oral dose } \\
\text { administration }\end{array}$ & $\begin{array}{l}\text { Enteral drug absorption is influenced by the } \\
\text { location of administration within the gastro- } \\
\text { intestinal tract }\end{array}$ & Oral, nasogastric tube, gastrostomy, duodenal tube \\
\hline Oral feeding status & $\begin{array}{l}\text { Critical illness is associated to gastrointestinal } \\
\text { dysmotility and food intolerance }\end{array}$ & Oral feeding status within the $24 \mathrm{hr}$ prior to microtracer \\
\hline \multirow[t]{3}{*}{ Comedication } & Slowing absorption & Opioids \\
\hline & Increasing absorption & Prokinetics \\
\hline & Influences absorption & Vasopressor and inotropic drugs \\
\hline
\end{tabular}

PELOD $=$ pediatric logistic organ dysfunction.

administration of the microtracer and for one patient treatment acetaminophen dosing information was missing, leaving 47 evaluable patients with a median age of 6.1 months (interquartile range [IQR], 1.8-20 mo) and a median bodyweight of $7.4 \mathrm{~kg}(\mathrm{Q} 1-\mathrm{Q} 3,4.3-10.5 \mathrm{~kg})$. Patient characteristics and treatment are described in Table 2. Thirty-seven patients (78.7\%) had been admitted for postoperative care. The median Pediatric Risk of Mortality score was 16 (Q1-Q3, 5-29).

\section{Dataset}

Supplemental Figure 2 (Supplemental Digital Content 3, http:// links.lww.com/CCM/E945; legend, Supplemental Digital Content 5, http://links.lww.com/CCM/E947) shows the concentration-time profile of the complete dataset including 250 and 314 radiolabeled and treatment acetaminophen concentrations, respectively. Twenty-three measurements below the limit of quantification (BLOQ) and two upper the limit of quantification for radiolabeled and treatment acetaminophen, respectively, were excluded from the dataset as these measurements represented less than $10 \%$ of the total number of available measurements $\left(8.4 \%\right.$ and $0.6 \%$ for $\left[{ }^{14} \mathrm{C}\right]$ acetaminophen and treatment acetaminophen, respectively). The median numbers of concentrations per patient included in the analysis were six (Q1-Q3, 5-6) and seven (Q1-Q3, 6-8) for $\left[{ }^{14} \mathrm{C}\right]$ acetaminophen and treatment acetaminophen, respectively.

\section{Pharmacokinetics Model}

A two-compartment model best described the time course of oral ${ }^{14} \mathrm{C}$ microtracer and IV treatment acetaminophen blood concentrations. The mean oral bioavailability in the population 
TABLE 2. Patients' Characteristics and Treatment $(n=47)$

$\begin{array}{lc}\begin{array}{l}\text { Patients' Characteristics } \\ \text { and Treatments }\end{array} & \text { Values } \\ \begin{array}{l}\text { Patient characteristics } \\ \text { Age (mo) }\end{array} & 6.1(1.8-20) \\ \text { Weight (kg) } & 7.4(4.3-10.5) \\ \quad \begin{array}{l}\text { Normalized weight for age ( } z \text { score), } \\ \quad \text { mean (sD) }\end{array} & -0.7(1.2) \\ \text { Sex, male, } n(\%) & 38(80.9) \\ \text { Gestational age (wk) } & 39.9(38-40) \\ \quad \text { Mortality rate, } n \text { (\%) } & 0(0) \\ \quad \text { Mechanical ventilation on study day, } & 20(42.6) \\ \quad n(\%) & 3.8(0.9-9.2)\end{array}$

Severity scores

Pediatric logistic organ dysfunction (on study day)

$10(1-11)$

Pediatric Index of Mortality II score

$0.92(0.2-3.88)$

Pediatric Risk of Mortality

$16(5-29)$

Diagnostic, $n(\%)$

Surgical (total)

37 (78.7)

Of which abdominal surgery

12 (25.5)

Medical

$10(21.3)$

Way of oral acetaminophen administration, $n$ (\%)

Oral

14 (29.8)

Nasogastric tube

$22(46.8)$

Duodenal

$8(17.0)$

Gastrostomy

Orally fed patients ${ }^{\mathrm{a}}, n$ (\%)

$23(48.9)$

Comedications, $n(\%)$

Prokinetics

Opioids $43(91.5)$

Vasoactive-inotropic drugs

$13(27.7)$

Laboratory values at infusion start

Urea $(\mathrm{mmol} / \mathrm{L})$

$3.5(2.3-4.9)$

Creatinine ( $\mu \mathrm{mol} / \mathrm{L})$

$23(18-34)$

Alanine aminotransferase (U/L)

$16(10-24)$

Gamma-glutamyltransferase (U/L)

$20(10-71)$

Alkaline phosphatase (U/L)

$151(127-197)$

Leucocyte count $\left(10^{9}\right.$ per L)

$10.6(8.1-13.8)$

C-reactive protein $(\mathrm{mg} / \mathrm{L})$

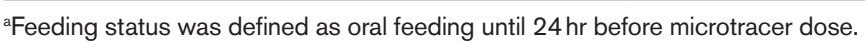
Values are expressed as median and (Q1-Q3) unless specified otherwise.

TABLE 3. Variable Estimates From the Structural and Final Model With Bootstrap Results

\begin{tabular}{llc} 
Variable & $\begin{array}{c}\text { Model Variables } \\
\text { Estimates } \\
\text { (RsE \%) } \\
\text { (Shrinkage \%) }\end{array}$ & $\begin{array}{c}\text { Bootstrap } \\
\text { Mean } \\
\text { (Bootstrap } \\
\text { RsE \%) }\end{array}$ \\
\hline Bioavailability & & \\
F & $0.718(6)$ & $0.718(6)$
\end{tabular}

Absorption rate constant

$$
\mathrm{ka}\left(\mathrm{h}^{-1}\right)
$$$$
2.15(27)
$$$$
2.25(32)
$$

Clearance

$$
\begin{array}{lll}
\mathrm{CL} & \mathrm{CL}=\mathrm{TVCL} \times(\mathrm{BW} / 7.4) \Theta_{\mathrm{CL}} \\
\operatorname{TVCL}\left(\mathrm{L} \cdot \mathrm{h}^{-1} \cdot 7.4 \cdot \mathrm{kg}^{-1}\right) & 1.95(6) & 1.94(7) \\
\Theta_{\mathrm{CL}} & 1.05(12) & 1.06(12)
\end{array}
$$

Inter-compartmental clearance

$$
\mathrm{Q}
$$

$$
\mathrm{Q}=\mathrm{TVO} \times(\mathrm{BO} / 7.4)
$$

TVO $\left(L \cdot h^{-1} \cdot 8.6 \mathrm{~kg}^{-1}\right)$

$$
0.346 \text { (12) }
$$

Volumes of distribution

$$
\text { V1 }
$$$$
\text { TVV1 }\left(L \cdot 8.6 \mathrm{~kg}^{-1}\right)
$$$$
\mathrm{V} 1=\mathrm{TVV} 1 \times(\mathrm{BW} / 7.4) \Theta_{\mathrm{V} 1}
$$

V2

$$
\Theta_{\mathrm{v} 2}\left(\mathrm{~L} \cdot 8.6 \mathrm{~kg}^{-1}\right)
$$$$
0.702(15)
$$$$
\mathrm{V} 2=\mathrm{V} 1 \times \Theta_{\mathrm{V} 2}
$$$$
0.502(21)
$$

Inter-individual variability
$\omega \mathrm{CL}$
0.114 (23) (7)
$0.109(24)$
$\omega \mathrm{ka}$
2.45 (30) (20)
$\omega \mathrm{F}$
$1.31(35)(22)$
$1.28(37)$

Residual error
Exponential error therapeutic acetaminophen

Exponential error radiolabeled acetaminophen

$$
\begin{aligned}
& 0.224(16)(5) \\
& 0.102(19)(16)
\end{aligned}
$$$$
0.218(16)
$$

$\omega=$ interindividual variability, $\Theta$ = estimated allometric exponent for clearance, $\Theta_{v 1}=$ estimated allometric exponent for the central volume of distribution, $\Theta_{v_{2}}=$ fraction of the population central volume of distribution representing the population peripheral volume of distribution, $\mathrm{BW}=$ body weight, $\mathrm{CL}=$ population clearance, $\mathrm{F}=$ oral bioavailability, $\mathrm{Q}=$ population inter-compartmental clearance, $\mathrm{RSE}=$ residual SE, TVCL $=$ typical population clearance for a $7.4 \mathrm{~kg}$ child, TVQ = typical population inter-compartmental clearance, TVV1 = typical population central volume of distribution, $\mathrm{V} 1=$ population central volume of distribution, $\mathrm{V} 2$ = population peripheral volume of distribution.

Typical population values correspond to the population variable for a child of $7.4 \mathrm{~kg}$.

was 72\% (bootstrap 95\% CI, 64-79\%) with a high interindividual variability: individual bioavailability estimates ranged from $11 \%$ to $91 \%$, implying that some patients absorbed only around $10 \%$ of the oral doses while in others the absorption 
was almost complete. The other pharmacokinetics variables are provided in Table 3. The IV data were similar as previously reported (26), including similar pharmacokinetics variable relationship with weight over the first and third IQR. Detailed comparison of the model variables with literature values can be found in eMethods (Supplemental Digital Content 1, http:// links.lww.com/CCM/E943) and eResults (Supplemental Digital Content 4, http://links.lww.com/CCM/E946).

Bodyweight was the best predictor of clearance and volume of distribution. After inclusion of bodyweight in the model, age and other potential covariates tested were not found to be significant.

The interindividual variability in bioavailability could not be explained by any patient characteristic. The minimum, 5th, 50th, and 95th percentile and the maximum individual enteral bioavailability estimates in our analysis were $0.11,0.34,0.72,0.90$, and 0.91 respectively. As illustrated in supplementary 1 in the eResults (Supplemental Digital Content 4, http://links.lww.com/CCM/ E946), feeding status and the characteristics of the route of enteral administration (oral, nasogastric, duodenal, and gastrostomy) did not significantly impact bioavailability. Moreover, abdominal surgery was also not a significant explanatory variable for bioavailability. Table 3 describes variable estimates of the final model. All internal validation presented in the eResults (Supplemental Digital Content 4, http://links.lww.com/CCM/E946) shows that the model described the data accurately and precisely.

\section{Simulation}

Figure 1 shows the median and the $90 \%$ prediction intervals of the simulated plasma concentrations over 24 hours after acetaminophen administration. Exposure after standard similar IV and oral doses $(15 \mathrm{mg} / \mathrm{kg}$ every $6 \mathrm{hr}$ ) led to adequate Css with the IV route (median mean Css corresponded to the targeted mean Css of $10 \mathrm{mg} / \mathrm{L}$ ). Nevertheless, most patients were below the targeted blood concentrations with the same oral standard doses (median mean Css around $6.5 \mathrm{mg} / \mathrm{L}$ ). Patients were 2.5 times more likely to reach targeted blood concentrations with IV than with oral administration. The highest oral dosing of $90 \mathrm{mg} / \mathrm{kg} / \mathrm{d}$ potentially leads to adequate Css, but patients with bioavailability

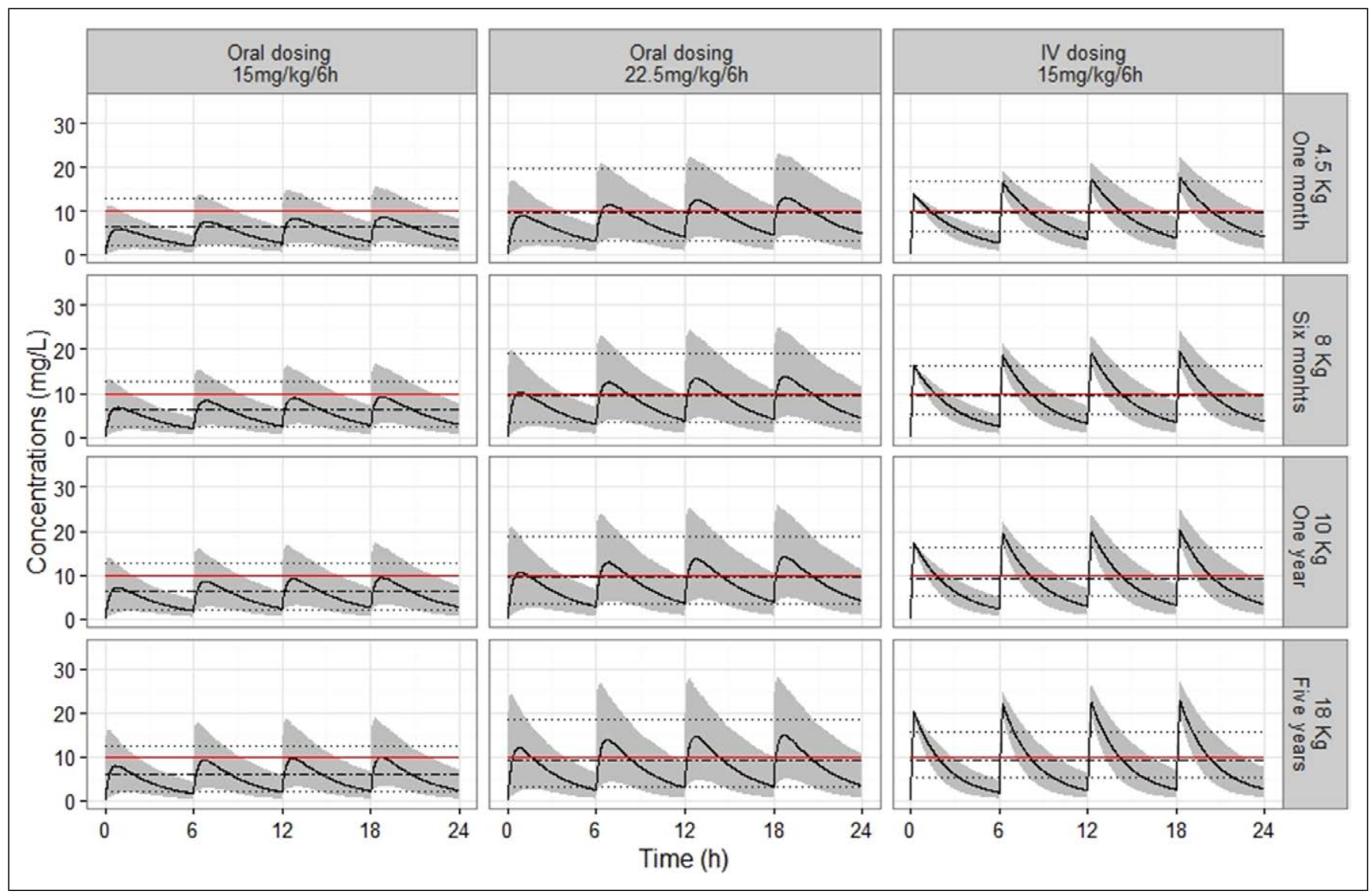

Figure 1. Simulated acetaminophen concentration-time profiles over $24 \mathrm{hr}$ after standard oral dose $(60 \mathrm{mg} / \mathrm{kg} / \mathrm{d}-\mathrm{left})$, high oral doses $(90 \mathrm{mg} / \mathrm{kg} / \mathrm{d}-$ middle), and IV dosing (right) in four age groups, that is, $1 \mathrm{mo}, 6 \mathrm{mo}, 1 \mathrm{yr}$, and $5 \mathrm{yr}$ of 4.5, 8, 10, and $18 \mathrm{~kg}$. The dashed line shows the median of the mean steady-state concentration and the lower and upper dotted lines indicate the 5th and the 95th percentiles of the mean steady-state concentration respectively. The red line represents the targeted steady-state concentrations. Doses recommended by the Lexicomp Pediatric and Neonatal Handbook (23) were used for the oral and IV standard doses and the Dutch Pediatric Drug Handbook (19) for the high oral dose (90 mg/kg/d). Wide variability is seen with oral dosing while IV dosing leads to less variable steady-state concentrations. The mean targeted steady-state concentrations of $10 \mathrm{mg} / \mathrm{L}$ are not reached with an oral dosing of $60 \mathrm{mg} / \mathrm{kg} / \mathrm{d}$ while the same IV dosing allows reaching adequate systemic exposure. With the highest recommended oral dose, the mean targeted steady-state concentrations are reached, but the important interindividual variability implies that some patients are underexposed and other overexposed. 
in the upper range have higher exposure than with $60 \mathrm{mg} / \mathrm{kg} / \mathrm{d}$ IV, and similarly, patients with bioavailability in the lower range would not reach targeted level. With $90 \mathrm{mg} / \mathrm{kg} / \mathrm{d}$ dosing, patients are still 1.4 times more likely to be within the targeted range after IV administration than after high oral administration.

\section{DISCUSSION}

Microtracer studies offer a new opportunity to rationalize drug dosing and choice of route of administration in the critically ill patient. In this stable PICU population studied, the mean oral bioavailability of acetaminophen was $72 \%$ with a very wide interindividual variability. When compared to the reported therapeutic range, the current oral dosing guidelines potentially result in underexposure in most patients, in contrast to IV administration. The estimated oral and IV pharmacokinetics variables are in line with previous estimates in children $(22,26)$. Similar variability has been shown in infants younger than 3 months (22) and in adults undergoing surgery (28). In the latter, oral administration also led to more variable blood concentrations than IV administration (28).

The median bioavailability in the current study was $72 \%$. Although the median enteral bioavailability in our analysis lies within the reported range in healthy adults of $60-97 \%$ as calculated by AUC (13-15), the range found in our analysis is much wider. Furthermore, the patients included in our analysis might present less pharmacokinetic variability than the overall PICU population due to inclusion criteria, meaning that an even higher variability in this population might be expected. Since the actual enteral bioavailability is not $100 \%$ but $72 \%$ or less in half of the patients included in our analysis, this can result in underexposure in a part of this population. We believe that dosing guidelines should actually reflect bioavailability. If only $72 \%$ of an oral dose reaches the systemic circulation, a one-third higher dose would be needed to reach the same blood level as with an IV dose. When simulating the plasma concentrations reached with different official dosing guidelines, we noticed that similar mean targeted Css were indeed reached with the highest recommended oral dose of $90 \mathrm{mg} / \mathrm{kg} / \mathrm{d}$ and an IV dose of $60 \mathrm{mg} / \mathrm{kg} / \mathrm{d}$. But due to the high interindividual variability in oral bioavailability, a dose of $90 \mathrm{mg} / \mathrm{kg}$ can still potentially lead to underdosing in patients with low bioavailability and overdosing in patients with high oral bioavailability. This dosage is recommended for short-term use only (maximum 2-3 d) $(19,29)$. This seems a rational advice in the light of our findings suggesting that a patient with a bioavailability within the upper range may be at risk of overdosing. To date, there is no upper therapeutic range reported for acetaminophen in the pediatric population. Due to the lack of information on the upper therapeutic range, dosing guidelines should lead to a concentration-time profile the closest possible to the efficacious concentration, as an increased exposure might lead to toxicity. Acute liver failure in children receiving regular acetaminophen within the therapeutic dose range has been described $(30,31)$. Known risk factors for acetaminophen-induced liver failure are acute illness, fasting, and comedication with a CYP2E1 inducer $(30,32)$. Whether bioavailability in the upper range is a risk of acetaminophen toxicity remains to be determined.
In the present study in 0 to 6-year-old children, we did not find a relationship between age and oral bioavailability. In most dosing guidelines, however, the ratio of advised oral to IV dosing guidelines increases with age $(23,33)$. Clinicians often assume that conditions for good oral drug absorption are met when critically ill patients tolerate oral feeds and are clinically stable (34). Interestingly, our study suggests that oral bioavailability of acetaminophen is independent of feeding status or disease severity, challenging this assumption.

The variable and unpredictable bioavailability of acetaminophen in critically ill children suggest that the IV route should be preferred for reliable and effective pain relief.

This study has several strengths. ${ }^{14} \mathrm{C}$ microtracer study design has been used in drug development in adults, but this is the first study in the PICU. This study design offers a new opportunity to study oral bioavailability in the PICU, where 15\% of drugs are given enterally without bioavailability data (9). It presents also opportunities to study other patient populations for which the traditional crossover study design is not feasible for practical and/or ethical reasons (e.g., patients with quickly changing disease severity, pregnant women, and elderly). In addition, our study provides guidance for acetaminophen dosing in the pediatric intensive care. Similar studies on other analgesics and sedatives like morphine, clonidine, or benzodiazepines would provide useful information to rationalize dosing in the PICU, particularly when switching from IV to oral administration.

The following limitations should be addressed. First, we cannot exclude that the oral microtracer dose has contributed to the lower bioavailability and large interindividual variability observed. Such a low dose may contribute to more unexplained variability than does a treatment dose. However, incomplete oral drug administration is highly unlikely as recovery of the drug from the administration in the feeding tube was almost 100\% (5). Also, saturation of intestinal drug metabolism with a treatment dose could have resulted in higher systemic exposure than with a microtracer dose alone. Both scenarios are unlikely, however, as our results are in line with an indirect marker of bioavailability, the oral to IV exposure ratio, that varies between $40 \%$ and $100 \%$ in different pediatric formularies $(19,23,33,35)$. Furthermore, similar pharmacokinetics results, that is, dose-linearity, have been obtained with acetaminophen oral microdose and therapeutic dose in adults $(36,37)$. Second, the current study was not designed to assess intra-individual variability in bioavailability that may influence acetaminophen exposure after multiple oral doses. Indeed, bioavailability was assessed on a single oral dose and then extrapolated to obtain Css. Third, it was not meant to assess the impact on acetaminophen effectiveness, and therefore, pharmacokinetics data should be seen as a surrogate endpoint. However, considering that a clear concentration-effect relationship has been established for acetaminophen (38), we believe that this study should motivate future studies comparing analgesic effect after oral and IV routes. A recent systematic review on the efficacy of oral versus IV acetaminophen in adults concluded that evidence is lacking to favor IV over oral 
administration (12). This review included only three randomized efficacy trials in adults: that is, one open-label study, one underpowered study, and one in day-case surgery. In contrast, data from our group showed a very significant morphine sparing effect with IV acetaminophen (approximately $70 \%$ less) in neonates and infants after major surgery (10). The morphine sparing effect did not occur with the use of the rectal route, which resulted in the same variable absorption and bioavailability as with the oral route $(39,40)$.

\section{CONCLUSIONS}

Using a microtracer study design, an innovative approach to study oral drug disposition in the real-life clinical situation in the intensive care, we show that oral acetaminophen bioavailability is lower than generally assumed, with a large interindividual variability in stable pediatric intensive care patients until 6 years. Oral dosing will likely results in an unpredictable, likely lower systemic exposure that may lead to increased risks of therapeutic failure. These data suggest that for the treatment of acute pain in children in the PICU, IV administration of acetaminophen may be preferable. Analgesic effect of oral versus IV acetaminophen should be compared in future studies.

\section{ACKNOWLEDGMENTS}

We thank Joke Dunk for her help in data collection. Also, we thank Ko Hagoort is thanked for editing the article.

\section{REFERENCES}

1. Zuppa AF, Barrett JS: Pharmacokinetics and pharmacodynamics in the critically ill child. Pediatr Clin North Am 2008; 55:735-755, xii

2. Smith BS, Yogaratnam D, Levasseur-Franklin KE, et al: Introduction to drug pharmacokinetics in the critically ill patient. Chest 2012; 141:1327-1336

3. Roberts DJ, Hall RI: Drug absorption, distribution, metabolism and excretion considerations in critically ill adults. Expert Opin Drug Metab Toxicol 2013; 9:1067-1084

4. Kleiber N, Tromp K, Mooij MG, et al: Ethics of drug research in the pediatric intensive care unit. Paediatr Drugs 2015; 17:43-53

5. Mooij MG, van Duijn E, Knibbe CA, et al: Pediatric microdose study of [(14)C]paracetamol to study drug metabolism using accelerated mass spectrometry: Proof of concept. Clin Pharmacokinet 2014; 53:1045-1051

6. Mooij MG, van Duijn E, Knibbe CAJ, et al: Successful use of [14C] paracetamol microdosing to elucidate developmental changes in drug metabolism. Clin Pharmacokinet 2017; 56:1185-1195

7. Leonowens C, Pendry C, Bauman J, et al: Concomitant oral and intravenous pharmacokinetics of trametinib, a MEK inhibitor, in subjects with solid tumours. Br J Clin Pharmacol 2014; 78:524-532

8. Turner MA, Mooij MG, Vaes WH, et al: Pediatric microdose and microtracer studies using 14C in Europe. Clin Pharmacol Ther 2015; 98:234-237

9. Mooij MG: Evolution in Pediatric Pharmacology. Rotterdam, The Netherlands, Erasmus University, 2016

10. Ceelie I, de Wildt SN, van Dijk M, et al: Effect of intravenous paracetamol on postoperative morphine requirements in neonates and infants undergoing major noncardiac surgery: $A$ randomized controlled trial. JAMA 2013; 309:149-154

11. Ceelie I, van der Starre C, Tibboel D, et al: Evaluation of drug formularies for pediatric intensive care. Pediatr Crit Care Med 2011; 12:e14-e19
12. Jibril F, Sharaby S, Mohamed A, et al: Intravenous versus oral acetaminophen for pain: Systematic review of current evidence to support clinical decision-making. Can J Hosp Pharm 2015; 68:238-247

13. Rawlins MD, Henderson DB, Hijab AR: Pharmacokinetics of paracetamol (acetaminophen) after intravenous and oral administration. Eur $J$ Clin Pharmacol 1977; 11:283-286

14. Eandi M, Viano I, Ricci Gamalero S: Absolute bioavailability of paracetamol after oral or rectal administration in healthy volunteers. Arzneimittelforschung 1984; 34:903-907

15. Atkinson HC, Stanescu I, Frampton C, et al: Pharmacokinetics and bioavailability of a fixed-dose combination of ibuprofen and paracetamol after intravenous and oral administration. Clin Drug Investig 2015; 35:625-632

16. Wong I, St John-Green C, Walker SM: Opioid-sparing effects of perioperative paracetamol and nonsteroidal anti-inflammatory drugs (NSAIDs) in children. Paediatr Anaesth 2013; 23:475-495

17. Akcan-Arikan A, Zappitelli M, Loftis LL, et al: Modified RIFLE criteria in critically ill children with acute kidney injury. Kidney Int 2007; 71:1028-1035

18. Lappin G, Kuhnz W, Jochemsen R, et al: Use of microdosing to predict pharmacokinetics at the therapeutic dose: Experience with 5 drugs. Clin Pharmacol Ther 2006; 80:203-215

19. Kinderformularium (Dutch Pediatric Handbook).2015. Available at: https://www.kinderformularium.nl. Accessed September 1, 2019

20. van Duijn E, Sandman H, Grossouw D, et al: Automated combustion accelerator mass spectrometry for the analysis of biomedical samples in the low attomole range. Anal Chem 2014; 86:7635-7641

21. Higton D, Young G, Timmerman P, et al: European Bioanalysis Forum recommendation: Scientific validation of quantification by accelerator mass spectrometry. Bioanalysis 2012; 4:2669-2679

22. Anderson BJ, Woollard GA, Holford NH: A model for size and age changes in the pharmacokinetics of paracetamol in neonates, infants and children. Br J Clin Pharmaco/ 2000; 50:125-134

23. Lexicomp Online: Pediatric and Neonatal Lexi-Drugs Online, Hudson: Wolters Kluwer Clinical Drug Information. Available at: https://online. lexi.com/lco/action/login. Accessed September 1, 2017

24. Anderson BJ, Holford NH, Woollard GA, et al: Perioperative pharmacodynamics of acetaminophen analgesia in children. Anesthesiology 1999; 90:411-421

25. Anderson B, Kanagasundarum S, Woollard G: Analgesic efficacy of paracetamol in children using tonsillectomy as a pain model. Anaesth Intensive Care 1996; 24:669-673

26. Wang C, Allegaert K, Tibboel D, et al: Population pharmacokinetics of paracetamol across the human age-range from (pre)term neonates, infants, children to adults. J Clin Pharmacol 2014; 54:619-629

27. Zuppa AF, Hammer GB, Barrett JS, et al: Safety and population pharmacokinetic analysis of intravenous acetaminophen in neonates, infants, children, and adolescents with pain or fever. J Pediatr Pharmacol Ther 2011; 16:246-261

28. Langford RA, Hogg M, Bjorksten AR, et al: Comparative plasma and cerebrospinal fluid pharmacokinetics of paracetamol after intravenous and oral administration. Anesth Analg 2016; 123:610-615

29. Sullivan JE, Farrar HC: Fever and antipyretic use in children. Pediatrics $2011 ; 127: 580-587$

30. Alonso EM, Sokol RJ, Hart J, et al: Fulminant hepatitis associated with centrilobular hepatic necrosis in young children. J Pediatr 1995; 127:888-894

31. Rivera-Penera T, Gugig R, Davis J, et al: Outcome of acetaminophen overdose in pediatric patients and factors contributing to hepatotoxicity. J Pediatr 1997; 130:300-304

32. Marzuillo P, Guarino S, Barbi E: Paracetamol: A focus for the general pediatrician. Eur J Pediatr 2014; 173:415-425

33. Paediatric Formulary Committee: British National Formulary for Children (BNF for Children). London, Pharmaceutical Press, 2016

34. Wheeler DS, Wong HR: Pediatric Critical Care Medicine: Basic Science and Clinical Evidence. London, Springer Science \& Business Media, 2007, p 1609

35. van der Zanden TM, de Wildt SN, Liem Y, et al; Dutch Paediatric Pharmacotherapy Expertise Network NKFK (Nederlands Kenniscentrum voor Farmacotherapie bij Kinderen): Developing a paediatric drug formulary for the Netherlands. Arch Dis Child 2017; 102: 357-361 
36. Lappin G, Shishikura Y, Jochemsen R, et al: Comparative pharmacokinetics between a microdose and therapeutic dose for clarithromycin, sumatriptan, propafenone, paracetamol (acetaminophen), and phenobarbital in human volunteers. Eur J Pharm Sci 2011; 43:141-150

37. Garner CR, Park KB, French NS, et al: Observational infant exploratory [(14)C]-paracetamol pharmacokinetic microdose/therapeutic dose study with accelerator mass spectrometry bioanalysis. $\mathrm{Br} \mathrm{J}$ Clin Pharmacol 2015; 80:157-167
38. Gibb IA, Anderson BJ: Paracetamol (acetaminophen) pharmacodynamics: Interpreting the plasma concentration. Arch Dis Child 2008; 93:241-247

39. van der Marel CD, Peters JW, Bouwmeester NJ, et al: Rectal acetaminophen does not reduce morphine consumption after major surgery in young infants. $\mathrm{Br} J$ Anaesth 2007; 98:372-379

40. Prins SA, Van Dijk M, Van Leeuwen $P$, et al: Pharmacokinetics and analgesic effects of intravenous propacetamol vs rectal paracetamol in children after major craniofacial surgery. Paediatr Anaesth 2008; 18:582-592 